\title{
Comparison of healthfulness of conventional meats and edible insects in Sub-Saharan Africa using three nutrient profiling models
}

Johnson Weru ${ }^{1,2^{*}} \mathbb{D}$, Peter Chege ${ }^{3}$, Anthony Wanjoya ${ }^{4}$ and John Kinyuru ${ }^{2}$

\begin{abstract}
Background: Meat and meat products have been blamed for a myriad of problems facing human kind like lifestyle illnesses, environmental degradation, and climate change. Edible insects have been suggested as the suitable alternatives to conventional meats in order to ameliorate these drawbacks. Healthfulness is the ability for a given food to impart health benefits to the consumer. Evidence is however scanty on the healthfulness of both the meats and edible insects in order to have grounds for replacing meats with insects in the diet. This study aimed to comparatively evaluate the healthfulness of meats and edible insects in Sub-Saharan Africa using modern nutrient profiling models.
\end{abstract}

Materials and methods: Nutritional data for meats and edible insects were obtained from Food Composition Tables (FCTs) and a systematic review, respectively. The data was applied to three nutrient profiling models: the WXYfm (Ofcom) model that was designed to regulate advertising of foods to children, the RRR (Ratio of Recommended to Restricted) model that assesses the ratio of positive to negative nutrients in foods, and the GDA (Guideline Daily Amounts) model which has been used to regulate health claims on foods. Tukey's Studentized Range (HSD) Test (The SAS System) was used to check for significance in differences of healthfulness using mean scores.

Results: The WXYfm model classified all foods as healthful, and Nasutitermes spp. was significantly more healthful than duck ( $P=0.05)$. The RRR classified all foods as healthful, and Nasutitermes spp. was significantly more healthful than all other foods except Macrotermes bellicosus and tilapia ( $P=0.05)$. Duck (for women and men) and pork (for women), were classified as unhealthful by the GDA scoring system, and duck was significantly less healthful than all other foods $(P<0.0001)$, except for pork and mutton.

Conclusion: Edible insects are promising alternatives to conventional meats, but the choice should be on a speciesto-species basis. This would be significant in broadening the choice of protein sources to cater for an ever-increasing world population.

Keywords: Meat, Edible insects, Healthfulness, Nutrient profiling, Scores

\section{Background}

The term 'healthful' means promoting good health, e.g., food, while the term 'healthy' means in good health e.g., a healthy person. But the term 'healthy' has been used for both the person and the good food (Drewnowski 2005).

\footnotetext{
*Correspondence: jnweru@gmail.com

1 Department of Food Science, Nutrition and Technology, Karatina

University, Karatina, Kenya

Full list of author information is available at the end of the article
}

Healthfulness therefore implies the ability of a food to impart health benefits to the consumer. Meat is defined as the flesh (skeletal muscle) of animals that is eaten as food. This definition may include connective tissue and the fat attached to the muscle (Williams 2007). In culinary terms, meat is divided majorly into two categories; red meat and white meat. Red meat refers to meat from cattle, sheep, and goat (Williams 2007) while white meat is mainly from poultry (Cosgrove et al. 2005). Meat 
remains an important part of the human diet especially in the developed world (McAfee et al. 2010). Meat is nutrient dense (Cosgrove et al. 2005) with substantial amounts of protein, B vitamins, zinc, iron, and essential amino acids, and these nutrients are easily absorbed in the body (Avery 2004).

Red meat is an important source of highly digestible protein with raw red muscle meat containing 20-25 g protein/ $100 \mathrm{~g}$, having all essential amino acids and does not contain limiting amino acids; and $2-8 \mathrm{~g}$ fat $/ 100 \mathrm{~g}$ for lean meat, with virtually no carbohydrate. Red meat is a good source of omega-3 polyunsaturated fatty acids, essential vitamins and minerals. Mutton is particularly nutrient-dense, and is a rich source of thiamin, vitamins B6 and B12, iron, phosphorus and copper (Williamson et al. 2005; Williams 2007). Fish and shellfish are excellent sources of protein (13-22 g protein/ $100 \mathrm{~g}$ ) but are relatively poor in fat content $(1-23 \mathrm{~g}$ fat/100 g) and carbohydrate content ( $0-3 \mathrm{~g}$ carbohydrate/100 g) (Nurnadia et al. 2011). Chicken muscle meat provides 19-22 g protein/ $100 \mathrm{~g}$ and $0.3-0.9 \mathrm{~g}$ fat/ $100 \mathrm{~g}$ (Wattanachant et al. 2004). But even with this encouraging data on nutrient composition, there have been reports of association of red meat consumption with incidences of colon cancer and cardiovascular diseases, thereby creating a negative vibe towards meat consumption (McAfee et al. 2010). For the purposes of this paper, the term meats shall mean beef, pork, poultry, fish, game meat, and offal.

Edible insects have been consumed by humans since time immemorial and entomophagy is still practiced presently in the world, particularly in Africa, Asia and Latin America (Pali-Schöll et al. 2019). Insects are ubiquitous and are the most diverse group of organisms in life's history (Raheem et al. 2019). More than 1000 species of insects are consumed worldwide, providing nutrition and economic lifeline to many communities (Raheem et al. 2019). Most insects have higher protein content with similar digestibility compared to conventional livestock (Kinyuru 2009). The crude protein content of many insect species has been found to exceed $60 \%$. The house cricket [Acheta domesticus (L.)], for instance, was shown to surpass soy protein in terms of being a protein source when fed to weaning rats (Finke et al. 1989). Chen \& Akre (1994) found the weaver ant, a common insect in China, to contain $42-67 \%$ protein and being rich in amino acids. Some insects have been shown to have protein with superior solubility (Omotoso 2006) and some have been reported to have protein with high biological value (de Guevara et al. 1995; Solomon et al. 2008).

Edible insects can be a source of fat and fiber in the diet. For instance, termites contain, on average, 32\% fat and $5 \%$ fiber, while crickets have $13 \%$ fat and $10 \%$ fiber based on dry matter (Rumpold and Schlüter 2013). Edible insects are high in monounsaturated fatty acids and polyunsaturated fatty acids as well as vitamins such as riboflavin, panthothenic acid, biotin, and in some cases folic acid (Rumpold and Schlüter 2013). On fresh weight basis, the energy content of insects is on average comparable to meat from conventional livestock except for pork since it has high fat content (Durst and Johnson 2010). Insects are rich in minerals including copper, manganese, selenium, iron, calcium, zinc, and phosphorus, with a particularly high content of iron and zinc (Barker et al. 1998; Christensen et al. 2006; Kinyuru 2009; Rumpold and Schlüter 2013).

A different approach of looking at the nutritional value of foods, referred to as nutrient profiling, has been developed in the recent past. Nutrient profiling is the science of classifying foods according to their nutritional composition (Scarborough et al. 2007) for intentions related to promoting health and preventing disease (Rayner 2013; Maillot et al. 2008). Nutrient profiles are developed using different algorithms, referred to as nutrient profile models, which use food composition data (Quinio et al. 2007). It can be used in various situations, for instance, food labelling and its regulation, regulation of advertising (Scarborough et al. 2007), regulating commercial food marketing to consumers, promoting reformulation of food products, and regulation of nutrition and health claims on foods (Maschkowski et al. 2014). Nutrient profiling can be used to differentiate foods that are healthful from those that are less healthful (Scarborough et al. 2007). Therefore, they can assist consumers in making healthful dietary choices (Eržen et al. 2015) and hence useful in tackling under- and over-nutrition (Payne et al. 2015). The term 'healthful' means promoting good health, e.g., food, while the term 'healthy' means in good health e.g., a healthy person. But the term 'healthy' has been used for both the person and the good food (Drewnowski 2005).

A nutrient profiling system/model is a scoring tool based on the nutrient composition of a food according to scientific and reasonable standards (Townsend 2010). Nutrient profiling filters a huge quantity of nutritional data into a single convenient index or indicator (Arvaniti \& Panagiotakos 2008). Nutrient profile models are mostly based on (1) qualifying nutrients known to be beneficial to health (positive nutrients), mostly vitamins and minerals, (2) disqualifying nutrients (negative nutrients), mostly fats, added sugars, and sodium, or (3) the combination of both (Drewnowski and Fulgoni 2008). Some models, for example, the WXYfm model, use a simple scoring system where negative points are assigned for beneficial nutrients and positive points are assigned for negative nutrients based on the nutritional content of $100 \mathrm{~g}$ of food or drink, and the points are summed up 
(Rayner 2005). Certain cutoff points are determined and foods or drinks that score above the cutoffs are categorized as 'less healthful' (Miller et al. 2009). The general 'building blocks' for the models include: nutrients selection, reference amount, food category declination, and cut-off use. Nutrient selection is concerned about the balance between positive nutrients and negative nutrients and how many are to be included; reference amount is the basis for comparison, e.g. per $100 \mathrm{~g}$, per $100 \mathrm{kcal}$, per serving; food category declination is concerned about the likelihood of applying the same nutritional criteria (nutrient scores and/or thresholds) for all foods (across the board model) or specific criteria according to food category (category-wise model); and cut-off use suggest the likelihood of either allocating scores based on the nutrient composition or using threshold values for each nutrient (Garsetti et al. 2007).

Consumers have difficulty using food package labels to derive nutritional information and they need refined support in making dietary choices. Additionally, public health messages related to dietary choices are not fully embraced or understood by the general public, who invariably purchase food instead of nutrients (Masset 2012). Nutrient profile (NP) models can therefore furnish consumers with instant data on the levels or amounts of nutrients in individual foods and hence the ability to make quick decisions on food choice (Lobstein and Davies 2008).

This study evaluated the healthfulness of edible insects and commonly consumed meats in Sub-Saharan Africa using three nutrient profiling models; WXYfm (Ofcom), RRR (Ratio of Recommended to Restricted), and GDA (Guideline Daily Amounts). The WXYfm model was developed by the Food Standards Agency (FSA) in the UK with an aim of controlling advertising of food to children. It is a scoring system where points are assigned based on the nutritional value in $100 \mathrm{~g}$ of the food or drink. It uses the following nonbeneficial nutrients; energy, total sugar, saturated fat and sodium; and counterbalances with beneficial nutrients, namely fruits, vegetables and nuts (FVN), fiber and protein. The model classifies foods 'across the board' (Scarborough et al. 2010) as either healthful, intermediate, or less healthful (Quinio et al. 2007).

The Ratio of Recommended to Restricted (RRR) model is a tool that provides a summary of the ratio of beneficial food components that should be eagerly consumed, i.e., protein, dietary fiber, calcium, iron, vitamins $\mathrm{A}$ and $\mathrm{C}$, to those that should be limited, i.e., energy (calories), sugars, cholesterol, saturated fat, and sodium. The RRR provides a single index that denotes this ratio which consumers can use to compare the nutritional value of food items as opposed to the complexity of interpreting multiple numeric values on food labels, recommendations or standards. The RRR is designed to help consumers make healthful food choices and it can identify nutrient-rich foods within food categories (Scheidt and Daniel 2004). The details of the development and application of the RRR model are available here (Scheidt and Daniel 2004).

The GDA Model is a LIM scoring system based on three nutrients to limit: fat, salt, and saturated fatty acids (SFA), with the output being a mean percentage score. It is based on maximum recommended daily amounts of the three nutrients in $100 \mathrm{~g}$ of food. The LIM score model is a threshold model which categorizes food as 'healthful' or 'less healthful' based on the amounts of negative nutrients and has been used as the basis for health claims on food labels, in addition to helping consumers reduce the intake of nutrients to limit (Scarborough et al. 2007).

The objective of this study was therefore to evaluate the healthfulness of edible insects and commonly consumed meats in Sub-Saharan Africa using three nutrient profiling models with a view of identifying the most healthful options for consumers to make informed and better dietary choices.

\section{Methods}

Nutrient composition data for meats and edible insects

Nutrient composition data of meats was obtained from Food Composition Tables (FCTs) available in the FAO INFOODS website, specifically those written in English, representing the three regions of Sub-Saharan Africa;

\section{i Tanzania Food Composition Tables \\ ii West African Food Composition Tables \\ iii Kenya Food Composition Tables \\ iv Lesotho Food Composition Tables \\ v Nigeria Food Composition Tables \\ vi Malawian Food Composition Tables \\ vii Mozambique Food Composition Tables}

Nutrient composition data was included if it was described as 'raw' or 'dried', under the meat category covering livestock, fish, and wildlife. All data lines with products described as processed, i.e., cooked, salted, braised, smoked, boiled, and broiled were excluded. Blood and fat/oil were also excluded in the nutrient composition data. All organ meats, e.g., heart, brain, etc. (with the exemption of liver) and nonspecific cuts of meat, e.g., chicken heads and legs, were clustered as offal. All missing values and those indicated as 'trace' or ' $T r$ ' were replaced with 0 . Data that was reported as a range was replaced with the median.

For all the foods that fulfilled the criteria above, data was extracted for energy and 11 macro- and micronutrients applicable in WXYfm, RRR, and GDA nutrient 
profiling models. The data was tabulated for each of the countries included, in readiness for calculating the final scores for each of the three nutrient profiling models. Nutrient composition data of edible insects was obtained through a systematic review by screening 483 published articles obtained from Google Scholar, PubMed, Scopus, and Web of Science, using criteria given by Kitchenham (2004), Popay et al. (2006), and Green et al. (2010). The articles were scrutinized for quality and inclusion using European Food Information Resource (EuroFIR) guidelines (Ifr et al. 2009; Payne et al. 2015). The detailed output of the systematic review has been published by Weru et al. (2021).

\section{Nutrient profiling}

For the WXY model, the points for both qualifying and disqualifying nutrients were allocated manually for each of the food items included. The final score for each food item was calculated by subtracting total points for qualifying nutrients from the total points of the disqualifying nutrients, while adhering to the protocols described in the model (Mike Rayner 2009). To give an example, if a food had values for energy $(\mathrm{KJ}) \leq 335$, saturated fat $(\mathrm{g}) \leq 1$, sodium $(\mathrm{mg}) \leq 90$, fiber $(\mathrm{g}) \leq 0.9$, and protein $(\mathrm{g}) \leq 1.6$, it would be allocated 0 (minimum) points for each of the five nutrients. The maximum points for disqualifying nutrients are 10 while highest points for qualifying nutrients is 5 . For instance, if a food had values for energy $(\mathrm{KJ})>3350$, saturated fat $(\mathrm{g})>10$, and sodium $(\mathrm{mg})>900$, then it would get 10 points for each of the three nutrients; and if fiber (g) $>4.7$, and protein $(\mathrm{g})>8$, then it would get 5 points for the each of the two nutrients. Therefore, if a food gets, say, 0 total points for disqualifying nutrients, and 5 total points for qualifying nutrients, then the final score would be -5 (0 minus 5 ).

To calculate the RRR scores, nutrient composition data was converted into \%DVs (percent Daily Values) based on a $2000 \mathrm{kcal}$ diet standard amounts. The final RRR scores were then calculated using the algorithm shown below:

$$
\begin{aligned}
\mathrm{RRR}= & \Sigma\left(\text { Nutrient }_{\text {recommended }} / 6\right) \\
& / \Sigma\left(\text { Nutrient }_{\text {restricted }} / 5\right) \\
& (\text { Scheidt and Daniel 2004) }
\end{aligned}
$$

where Nutrient ${ }_{\text {recommended }}$ includes protein, fiber, $\mathrm{Ca}, \mathrm{Fe}$,

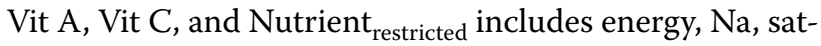
urated fat, and cholesterol.

We used the following algorithm to calculate the GDA scores:
Table 1 Guideline daily amounts used to calculate the LIM score. Source: (The Food and Drink Federation 2020)

\begin{tabular}{llll}
\hline Nutrient* & $\begin{array}{l}\text { Women } \\
(>\mathbf{1 9} \text { years) }\end{array}$ & Men (>19 years) & $\begin{array}{l}\text { Children } \\
\text { (5-10 years) }\end{array}$ \\
\hline Calories (kcal) & 20001 & 2500 & 1800 \\
Protein (g) & 45 & 55 & 24 \\
Carbohydrate (g) & 230 & 300 & 220 \\
Sugars (g) & 90 & 120 & 85 \\
Fat (g) & 70 & 95 & 70 \\
Saturated fat (g) & 20 & 30 & 20 \\
Fibre (g) & 24 & 24 & 15 \\
Salt (g) & 6 & 6 & 4
\end{tabular}

*The nutrients in bold font are those applicable for the calculation of GDA scores in meats and edible insects

$$
\begin{aligned}
& \mathrm{LIM}=\frac{\sum_{1}^{3} \text { ratio }_{j}}{3} \\
& \text { With } \text { ratio }_{j}=\left[\frac{\text { nutrient }_{j}}{\mathrm{MRV}_{j}}\right] \times 100
\end{aligned}
$$

where nutrient ${ }_{j}$ is the value, in grams, of the nutrient $j$ to limit in $100 \mathrm{~g}$ of food, and $\mathrm{MRV}_{j}$ is the maximum recommended daily value for nutrient $j$ based on GDA, as indicated in Table 1.

\section{Data analysis}

Tukey's Studentized Range (HSD) Test (The SAS System) was used to check for significance in differences of healthfulness using mean scores.

\section{Results}

The median and interquartile range of nutrient data used to calculate the WXYfm, RRR, and GDA scores of meats and edible insects is shown in Tables 2 and 3 respectively. The median values for energy were wide ranging for edible insects (range $=0.00-475.00 \mathrm{KCal}$ per $100 \mathrm{~g}$ ) compared to the meats (range $=82.00$ $274.00 \mathrm{KCal}$ per $100 \mathrm{~g}$ ). The interquartile range for energy was close for most of the products except a few edible insects which had wide ranging values, e.g., Tenebrio molitor (range $=0.00-444.00 \mathrm{KCal}$ per $100 \mathrm{~g}$ ). Energy, saturated fat, and sodium have a negative impact on the WXYfm score. The amount of saturated fat was relatively small across the products considering the maximum recommended daily intake of $20 \mathrm{~g}$. Data for saturated fat was scanty as depicted by median values, where $82 \%$ of all the products had median values of $0 \mathrm{~g}$ per $100 \mathrm{~g}$, while $51 \%$ of the total products had 


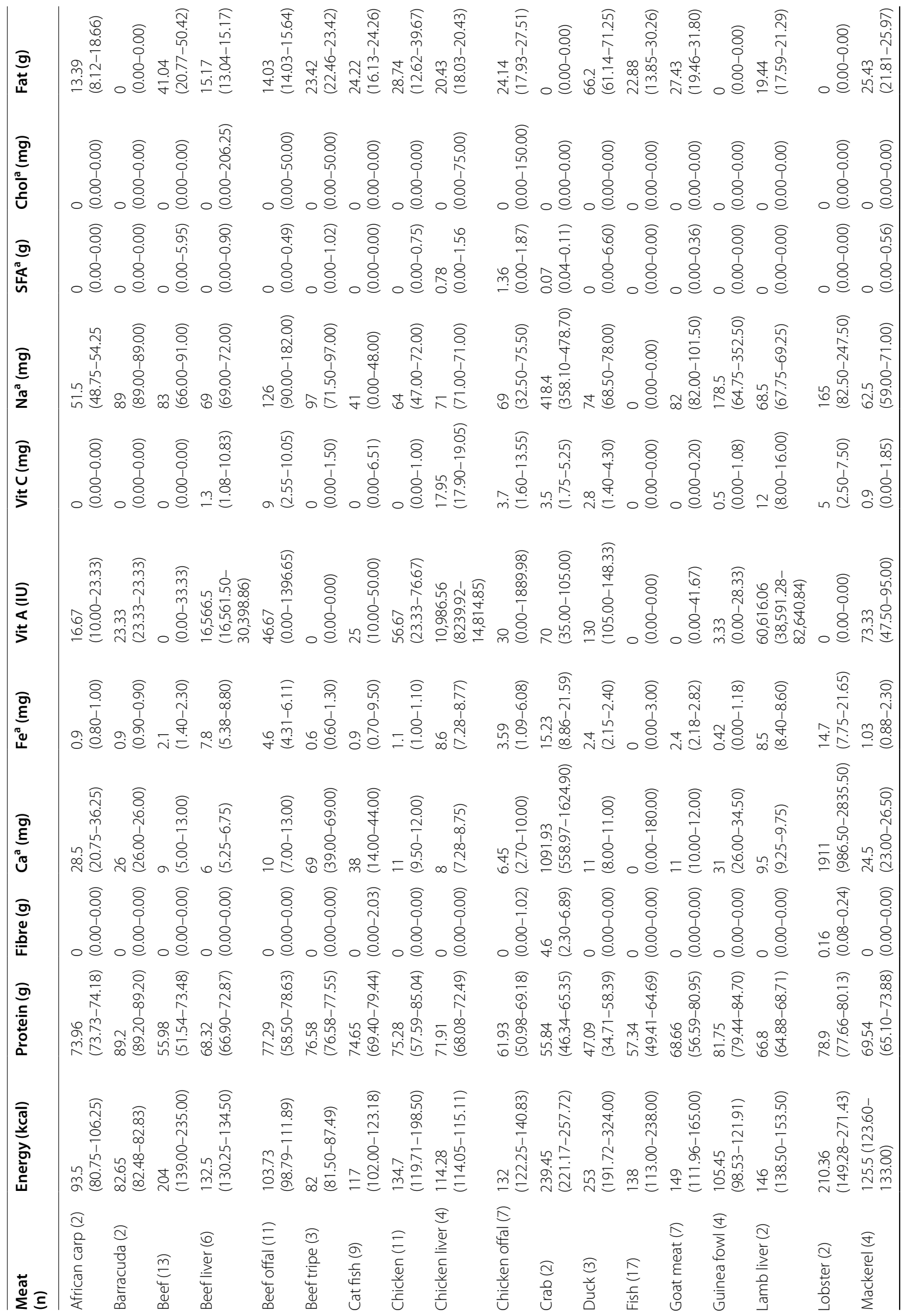




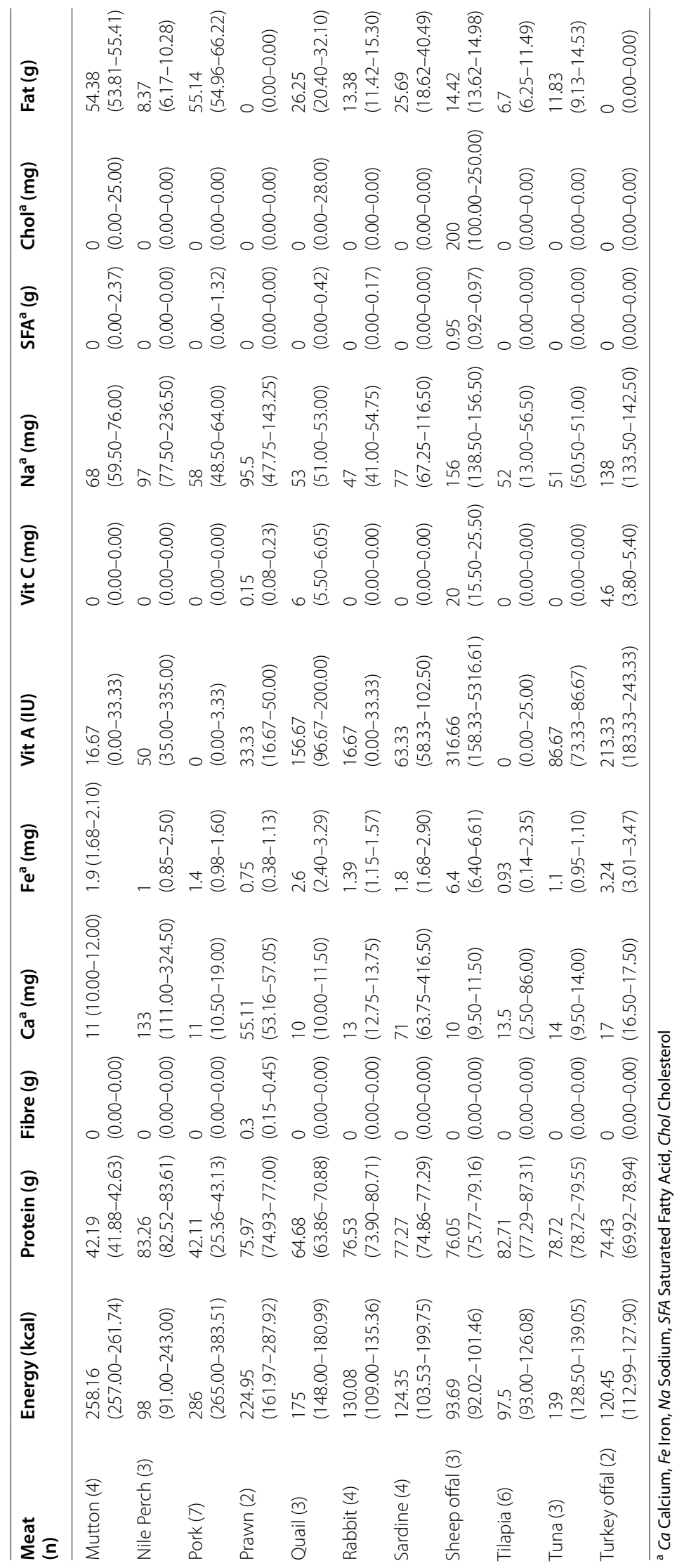




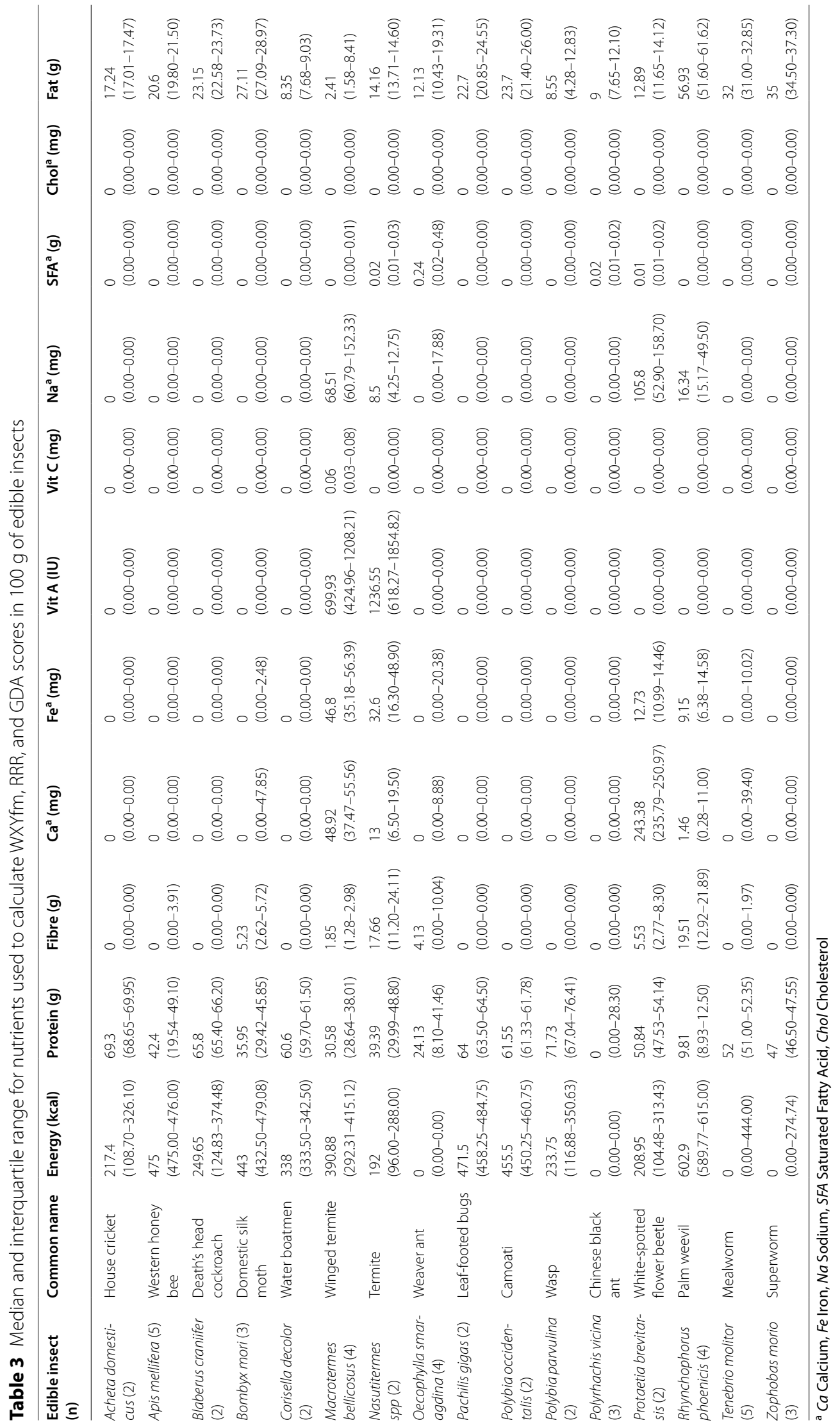




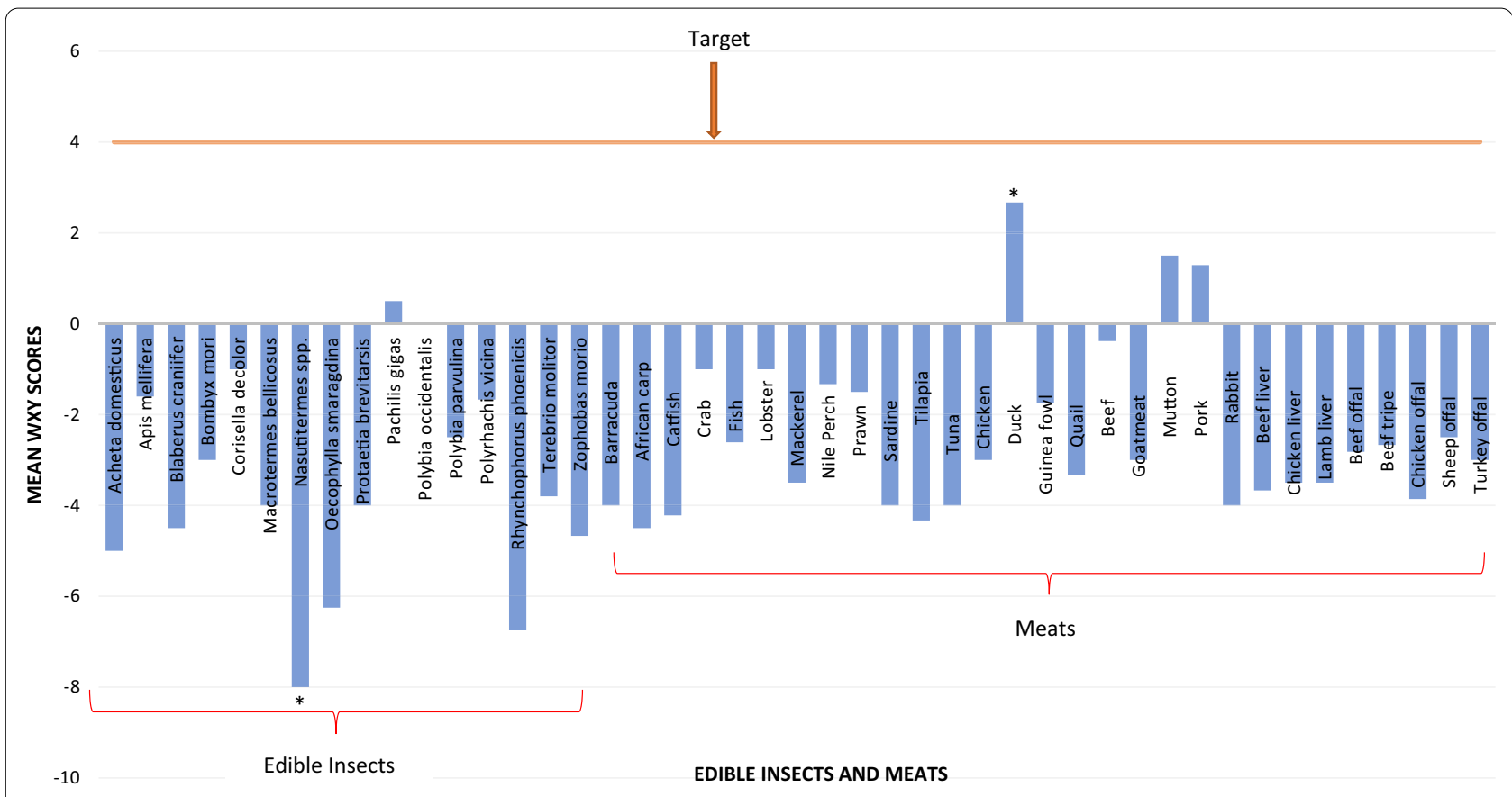

Fig. 1 Bar graph showing mean WXY scores for meats and edible insects. ${ }^{*}$ Nasutitermes spp. was significantly more healthful than duck ( $\left.P<0.001\right)$

25th and 75th percentile values of $0 \mathrm{~g}$ per $100 \mathrm{~g}$. The highest 75th percentile value for saturated fat was $6.6 \mathrm{~g}$ per $100 \mathrm{~g}$ for duck followed closely by beef at $5.95 \mathrm{~g}$ per $100 \mathrm{~g}$, which is far below the recommended daily intake of $20 \mathrm{~g}$. Most of the edible insects had no sodium while crab had the highest median sodium content of $418 \mathrm{mg}$ per $100 \mathrm{~g}$. Protein and fiber have a positive bearing on the WXYfm score. Only the edible insect Polyrhachis vicina had a median value of $0 \mathrm{~g}$ per $100 \mathrm{~g}$ of protein amongst all the products. The protein values were relatively high as depicted by $75.5 \%$ of the total food products being above $50 \mathrm{~g}$ per $100 \mathrm{~g}$ and therefore meeting the daily recommended value of $50 \mathrm{~g}$. However, edible insects had slightly lower median values for protein (range $=0.00-71.73 \mathrm{~g}$ per $100 \mathrm{~g}$ ) compared to all the other products (range $=42.00-89.20 \mathrm{~g}$ per $100 \mathrm{~g}$ ). The fiber content was scanty in that $80 \%$ of all the food items had median values of $0 \mathrm{~g}$ per $100 \mathrm{~g}$, with $71 \%$ of which had values of $0 \mathrm{~g}$ per $100 \mathrm{~g}$ at both 25th and 75th percentiles. This scenario impacts negatively on the WXYfm score.

Energy, saturated fat, sodium, and cholesterol are the nutrients with an undesirable impact on the RRR score. Cholesterol was absent in all the edible insects and scarcely present in the other meats. Sheep offal had the highest median value for cholesterol at $200 \mathrm{mg}$ per $100 \mathrm{~g}$, with a 75th percentile value of $250 \mathrm{mg}$ per $100 \mathrm{~g}$. Of the positive nutrients, it is notable that liver from beef, lamb, and chicken had very high median values for Vitamin
A (median $=16566.50,60616.06$, and $10986.56 \mathrm{IU}$ per $100 \mathrm{~g}$, respectively), surpassing in multiple times the daily recommended value of 2333 and 2000 IU for male and female adults, respectively. Vitamin $C$ was very little whereby $66.7 \%$ of the total products had a median value of $0 \mathrm{mg}$ per $100 \mathrm{~g}$, and $57.8 \%$ of all the food products had $0 \mathrm{mg}$ per $100 \mathrm{~g}$ at the 25th and 75th percentiles. Of the edible insects, $71 \%$ had a median value of $0 \mathrm{mg}$ per $100 \mathrm{~g}$ for both calcium and iron. Crab and lobster had the highest median values for calcium (median $=1091.38$ and $1191.00 \mathrm{mg}$ per $100 \mathrm{~g}$, respectively), while the edible insects Nasutitermes spp and Macrotermes bellicosus had the highest median content of iron (median $=32.60$ and $46.80 \mathrm{mg}$ per $100 \mathrm{~g}$, respectively).

Figure 1 presents the mean WXY scores for edible insects and meats. All the food products were classified as healthful by the WXYfm model, since the scores were below the cut-off point of 4 . The lower the score, the more healthful is the food. However, Nasutitermes spp. was significantly more healthful than duck $(P<0.001)$. Overall, Nasutitermes spp. was the most healthful (mean score $=-8.00 \pm 2.00)$ followed by Rhynchophorus phoenicis (mean score $=-6.75 \pm 3.25$ ). The most frequent mean score was -4 with $13.3 \%$ followed by -3 with $8.9 \%$. The following food items had similar scores and hence comparable healthfulness: Rhynchophorus phoenicis and Oecophylla smaragdina (- 6.75 \pm 3.25 , $6.25 \pm 2.39$ ); Zophobas morio, African carp, Blaberus craniifer, tilapia, and catfish $(-4.67 \pm 0.33$ to $-4.22 \pm 0.64)$; 


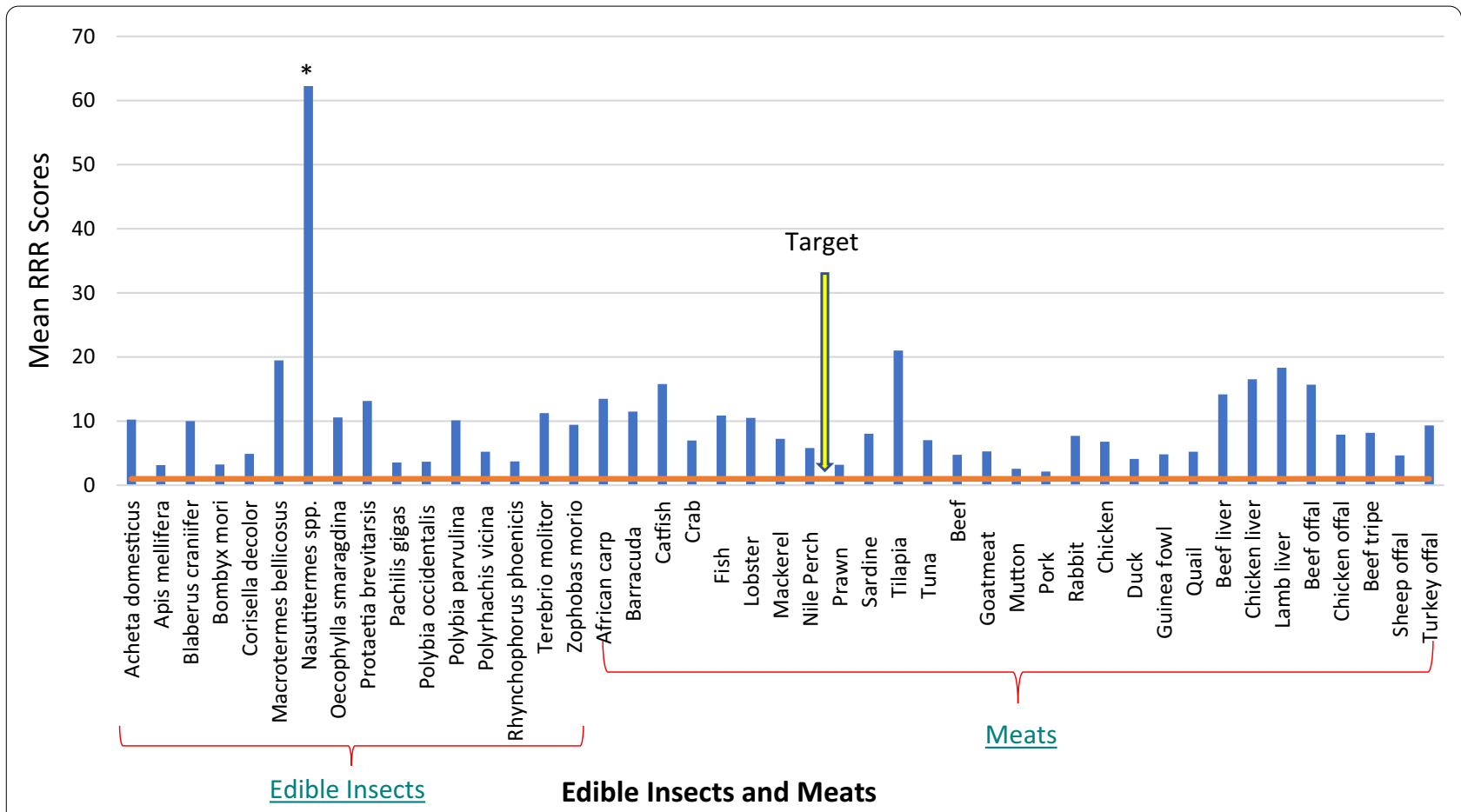

Fig. 2 Bar chart showing mean RRR scores for meats and edible insects. * Nasutitermes spp. was significantly more healthful than all other foods except Macrotermes bellicosus and tilapia $(P<0.0012)$

chicken offal and Terebrio molitor (- 3.86 \pm 0.59 , $3.80 \pm 1.83)$; beef offal, beef tripe, and fish $(-2.82 \pm 0.26$ to $-2.61 \pm 0.41$ ); and guinea fowl, Polyrhachis vicina, Apis mellifera, prawn, and Nile perch $(-1.75 \pm 1.44$ to $-1.33 \pm 2.19$ ). Some food items had exactly the same scores and therefore the same healthfulness: African carp and Blaberus craniifer ( $-4.50 \pm 0.50)$; barracuda, Macrotermes bellicosus, Protaetia brevitarsis, rabbit, sardine, and tuna $(-4.00 \pm 0.00)$; chicken liver, lamb liver, and mackerel $(-3.50 \pm 0.50) ;$ Bombyx mori, chicken, goatmeat, and turkey offal $(-3.00 \pm 0.00)$; and Corisella decolor, crab, and lobster $(-1.0 \pm 0.00)$.

The mean RRR scores for edible insects and meats are presented in Fig. 2. All of the food products were classified as healthful by the RRR scoring model, since the scores were above 1 . The higher the score, the more healthful is the food. The edible insect Nasutitermes spp. was significantly more healthful than all other foods except Macrotermes bellicosus and tilapia $(P<0.0012)$. Most $(60 \%)$ of the mean scores were below 10 with the least mean score being $3.15 \pm 0.71$. The following food items had similar mean scores and hence much the same healthfulness: pork and mutton (2.15 $\pm 0.56,2.57 \pm 1.02)$; Apis mellifera, prawn, Bombyx mori, Pachilis gigas, Polybia occidentalis, and Rhynchophorus phoenicis (3.15 $\pm 0.71-3.72 \pm 0.75$ ); duck, sheep offal, beef, guinea fowl, and Corisella decolor
(4.10 $\pm 3.41-4.89 \pm 0.18)$; quail, Polyrhachis vicina, goat meat, and Nile perch (5.23 $\pm 2.39-5.82 \pm 3.53)$; chicken and crab $(6.80 \pm 1.03,6.99 \pm 4.04)$; tuna, mackerel, rabbit, and chicken offal $(7.04 \pm 2.99-7.90 \pm 2.87)$; sardine and beef tripe $(8.04 \pm 2.45,8.19 \pm 3.12)$; turkey and Zophobas morio $(9.33 \pm 0.21,9.42 \pm 3.50)$ Blaberus craniifer, Polybia parvulina, Acheta domesticus, lobster, Oecophylla smaragdina, and fish (10.01 $\pm 6.67-10.86 \pm 2.41)$; Terebrio molitor and barracuda $(11.25 \pm 2.91,11.49 \pm 0.01)$; and, Protaetia brevitarsis and African carp (13.14 \pm 6.36 , $13.48 \pm 1.71)$.

Figure 3 shows the mean GDA scores for edible insects and meats. The cut-off point for GDA scores is 1 , hence any food with a score above 1 is unhealthful. The lower the score the more healthful is the food. Duck $($ mean $=1.310 \pm 0.470 \& 1.320 \pm 0.470$ for women and men, respectively) and pork (mean score $=1.008 \pm 0.132$, for women), were classified as unhealthful by the GDA scoring system. For children, the duck had a mean score of $0.950 \pm 0.320$ which is borderline unhealthful. Pork was classified as borderline unhealthful for men (mean score $=0.983 \pm 0.147$ ), same as mutton for women (mean score $=0.930 \pm 0.117)$. Duck was significantly less healthful than all other foods $(P<0.0001)$, except for pork and mutton. Acheta domesticus (mean score $=0.185 \pm 0.005$, for men), Corisella decolor (mean score $=0.120 \pm 0.020$, 


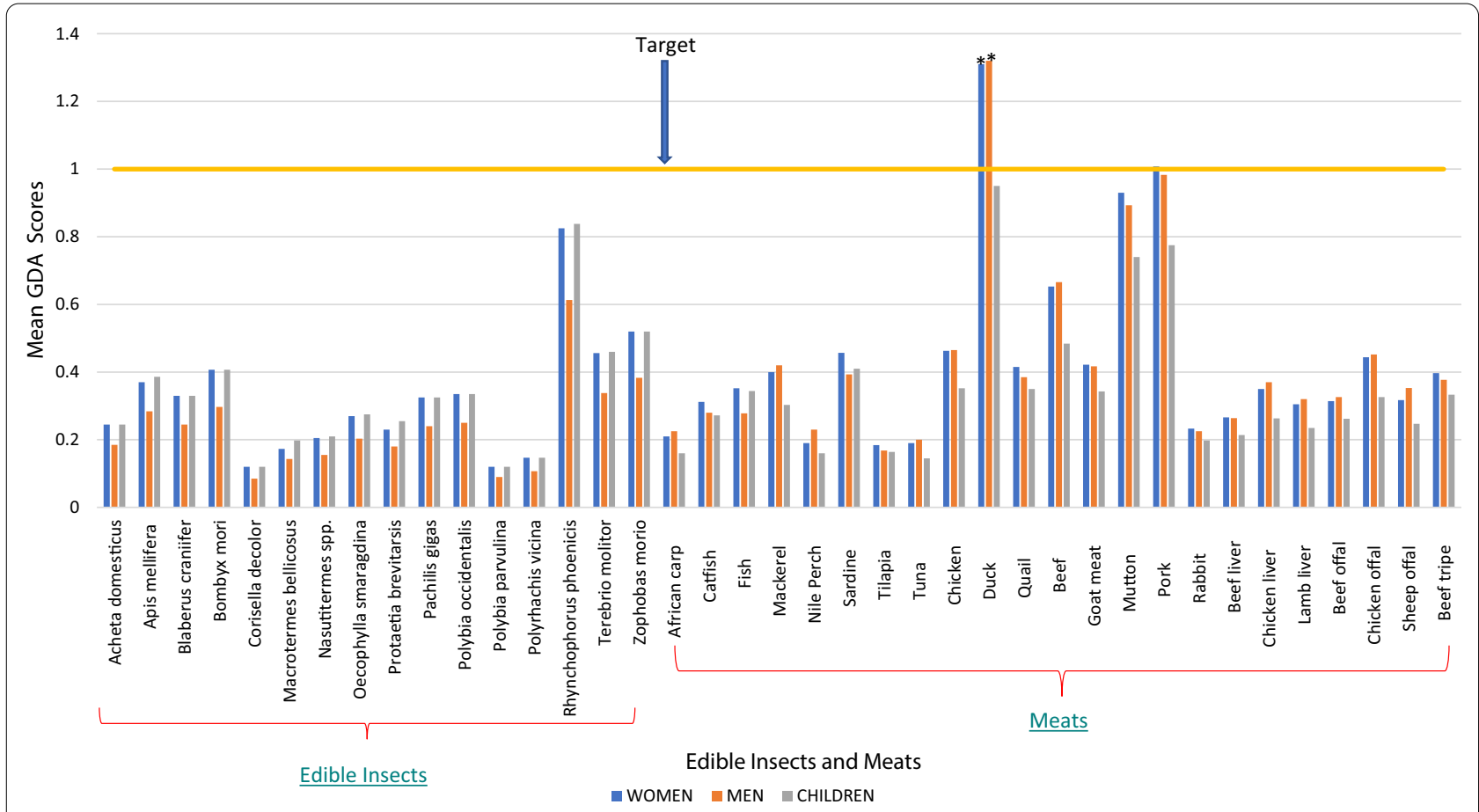

Fig. 3 Clustered column chart showing mean GDA scores for meats and edible insects. *Duck was significantly less healthful than all other foods $(P<0.0001)$, except for pork and mutton

$0.085 \pm 0.015$, \& $0.120 \pm 0.020$, for women, men and children, respectively), Macrotermes bellicosus (mean score $=0.173 \pm 0.123, \quad 0.143 \pm 0.099, \quad \& \quad 0.198 \pm 0.141$, for women, men and children, respectively), Nasutitermes spp. (mean score $=0.155 \pm 0.015$, for men), Protaetia brevitarsis (mean score $=0.180 \pm 0.070$, for men), Polybia parvulina (mean score $=0.120 \pm 0.120$, $0.090 \pm 0.090 \& 0.120 \pm 0.120$, for women, men and children, respectively), Polyrhachis vicina (mean score $=0.147 \pm 0.038, \quad 0.107 \pm 0.027, \quad \& \quad 0.147 \pm 0.038$, for women, men and children, respectively), African carp (mean score $=0.160 \pm 0.110$, for children), Nile perch (mean score $=0.190 \pm 0.071 \& 0.160 \pm 0.066$, for women and children, respectively), tilapia (mean score $=0.184 \pm 0.057, \quad 0.168 \pm 0.041, \quad \& \quad 0.164 \pm 0.060$, for women, men and children, respectively), tuna (mean score $=0.190 \pm 0.080$ \& $0.145 \pm 0.055$, for women and children, respectively), and rabbit (mean score $=0.198 \pm 0.032$, for children) were classified as the most healthful food items according to GDA model.

\section{Discussion}

This study is the first to compare the nutritional profiles and healthfulness of edible insects to that of meats in Sub-Saharan Africa using nutrient profiling models. The use of nutritional profiling models to determine the healthfulness of foods is an important technique in determination of health claims on foods, assessing the nutritional quality of foods, and in guiding consumers in making informed food choices (Quinio et al. 2007).

The study found that both edible insects and meats had varied nutritional contents. Edible insects had a more profound variation than meats, an observation that has been reported in a similar study (Payne et al. 2015). These differences in nutrient values can be attributed to the diversity in individual species traits (Nowak et al. 2016). The absence of sodium in edible insects is a vital impetus to encourage the adoption of insects in the daily diets since there is need to reduce sodium consumption so as to reduce diet-related diseases (Van Horn et al. 2016). Additionally, all the edible insects in the study had no cholesterol and this is good news for the promotion of edible insects to be consumed liberally. Reduced intake of cholesterol in diet has a beneficial outcome on cardiovascular health (Van Horn et al. 2016). Due to nutrient variability, promotion of edible insects' consumption should be species-specific. Fiber is an important food component having positive effects on human health (Anderson et al. 2009), but it was largely absent in foods under the current study. Though some few edible insects and crab contained some amount of fiber, the lack of fiber in these meats should be expected since fiber is principally a plant-based nutrient (Anderson et al. 2009). The presence of fiber in edible insects is largely due to their 
exoskeleton, which occurs in the form of chitin and constitutes up to $10 \%$ of their dry weight (Kinyuru et al. 2015; da Silva Lucas et al. 2020).

The WXYfm model classified all the food items as healthful since all the scores were below 4, with Nasutitermes spp. being the most healthful. Accordingly, all the foods evaluated using this model in this study can be promoted for consumption by everyone. However, the specific edible insects would be a better choice since they scored significantly better than other meats. It would therefore be advisable to consider species-specific edible insects based on the healthfulness scores when promoting them as alternatives to meats. But this model did not classify edible insects as distinctively better alternatives to conventional meats as most of them shared similar scores with meats. For instance, based on healthfulness, barracuda, Macrotermes bellicosus, Protaetia brevitarsis, rabbit, sardine, and tuna would be chosen identically.

The RRR model classified all the food items as healthful and Nasutitermes spp.was significantly more healthful than all other foods, except Macrotermes bellicosus and tilapia. The choice of a better alternative food item within a food category can be determined by RRR model as demonstrated in this study. In the edible insects' category, Nasutitermes spp would be a better choice than Polyrhachis vicina. Similarly, liver from chicken, beef, and lamb are a better choice than duck and mutton, while the African carp is a better choice than the Nile perch. Making dietary choice is very intricate (Sobal and Bisogni 2009) and it is influenced by multidimensional factors with the most outstanding being healthfulness, sensory appeal, convenience, and price (Neacsu et al. 2017). This model has placed Nasutitermes spp on a pedestal, thus making it easy for consumers to identify a healthful alternative to other meats.

The LIM scoring system, GDA, used in the current study categorizes foods under three subgroups, viz. women, men, and children. The duck was classified as unhealthful for both women and men, and borderline unhealthful for children, while pork was classified as unhealthful for women and borderline unhealthful for men. Accordingly, duck is an unhealthful food choice and therefore should be consumed sparingly. It is not clear that insects would be a better choice in terms of healthfulness when compared to meats, except in relation to duck (women, men, and children), mutton (women and men), and pork (women and men). But, the choice of edible insects has additional non-nutritional benefits, including environmental conservation, animal welfare, and affordability (Machovina et al. 2015; Schönfeldt and Hall 2012). Further, meats have been associated with lifestyle-related illness like cardiovascular events, cancer, and diabetes (Schönfeldt and Hall 2012) in addition to environmental degradation with adverse effects on water sources, soil fertility, biodiversity, and climate (Machovina et al. 2015; Revell 2015).

In order to encourage consumption of foods from edible insects by non-traditional consumers, issues related to availability, acceptability-including palatability, the yuck factor, and regulatory framework need to be addressed (Pambo et al. 2018). A study carried out in Kenya on willingness to pay for termite-based food products, revealed that high nutritional value (healthfulness), food safety assurance, and recommendation by a nutritionist were positively correlated with purchase intentions, notwithstanding the existence of the custom of consuming edible insect (Alemu et al. 2015). It is therefore imperative to have concerted efforts from all the players, and especially producers of edible insects-based foods, nutritionists, and government regulators in augmenting the uptake of these novel foods. The nutritional and healthfulness benefits associated with edible insects should motivate the adoption of these unique food items in daily diets. In order to encourage entomophagy by the general population, the players in the food value chain, including food processors and caterers, can adopt these nutritious edible insects as novel food ingredients in recipes (Jasinski et al. 2019). Some communities in Nigeria already include edible insects as part of ingredients in their cuisine (Ebenebe et al. 2017). In tropical regions, where diets lack animal-source proteins and fats, entomophagy has bridged the gap by providing an affordable source of these essential nutrients, in addition to fighting hunger (Illgner et al. 2016).

When comparing the healthfulness outcome from the three models employed here, the study found that classification of the same foods is not identical across the models, but near similar. For instance, the WXY and RRR models classified Nasutitermes spp. as the most healthful, while GDA model classed Corisella decolor and Polybia parvulina as most healthful. On the other hand, GDA model gave duck (women and men) and pork (women) the verdict of being unhealthful. But as earlier mentioned, WXY and RRR did not classify any food as unhealthful, and consequently the duck and pork would be acceptable healthful-wise, according to these models. In a similar study that used data from Africa, Asia, The Pacific Islands, Europe, and North America, Tenebrio molitor and the larvae of Rhynchophorus phoenicis were classified as more healthful than beef and chicken using a different nutrient profiling model (Payne et al. 2015). It should be recognized that these models use different parameters and algorithms. So, the varied outcomes are not surprising. 


\section{Conclusions}

This study has elevated the need for considering the healthfulness of foods to enhance dietary choice for better nutrition. Foods can look nutritious based on the nutritional content but could be unhealthful and vice versa thereby misleading to consumers.

The call for replacing meats with edible insects therefore needs to be based on actual healthfulness of the specific foods. In this study, edible insects Nasutitermes spp., Corisella decolor and Polybia parvulina performed better in general compared to meats in regards to relative healthfulness. Except the duck and pork, all other meats were classified as healthful and thus, we cannot conclude that they should be avoided or removed from the diet. But it is important to compare their healthfulness so that one is able to select the better alternatives amongst the food items, thereby getting the full benefits of healthful choices.

Due to different parameters applied by various nutrient profiling models, it would be helpful to consider the purpose of each model before applying it to various foods. For instance, GDA is purely a LIM scoring system aimed at reducing the intake of nutrients to limit in our diets, and for regulating health claims on foods. Therefore, if the aim is to reduce negative nutrients in the diet, or to determine if a food should carry a health claim, then the GDA model should be chosen.

Finally, we hold the view that edible insects should be evaluated on a species-to-species basis when considering them as suitable alternatives to meats, in view of healthfulness alone. Beyond that, and seeing that none of them was classed as unhealthful, edible insects are a better choice than meats due to other non-nutritional benefits, are more sustainable, and do not present problems associated with lifestyle diseases.

\section{Abbreviations}

GDA: Guideline daily amounts; LIM: Limited; RRR: Ratio of recommended to restricted; MRV: Maximum recommended value.

\section{Acknowledgements}

Not applicable.

\section{Author's information}

Johnson Weru is a Ph.D. candidate at Jomo Kenyatta University of Agriculture and Technology, in the School of Food and Nutrition Sciences under Human Nutrition Sciences Department. He is also an assistant lecturer at Karatina University, School of Agriculture and Biotechnology, in the department of Food Science, Nutrition and Technology. He has interests in edible insects as alternative food sources for sustainable human nutrition and improved livelihoods. He is also interested in food safety and hygienic processing and preparation of foods.

\section{Authors' contributions}

JW was involved in designing of the study and data collection, plus drafting and formatting of the manuscript. PC proofread and edited the manuscript. AW carried out the statistical analysis of results' data. JN conducted literature review and contributed immensely in the design of the study. All the authors read and approved the manuscript.

\section{Funding}

We are greatly obliged to DAAD for providing funding for this research under the funding programme/-ID: In-Country/In-Region Scholarship Programme Kenya, 2017 (57376087). We declare that DAAD did not, in any way, take part in the design of the study, data collection and analysis, or interpretation of the results.

\section{Availability of data and materials}

The datasets generated during and/or analyzed during the current study are available from the corresponding author on reasonable request.

\section{Declarations}

Ethics approval and consent to participate

Not applicable.

\section{Consent for publication}

Not applicable.

\section{Competing interests}

The authors declare that they have no competing interests.

\section{Author details}

${ }^{1}$ Department of Food Science, Nutrition and Technology, Karatina University, Karatina, Kenya. ${ }^{2}$ Department of Food Science and Technology, Jomo Kenyatta University of Agriculture and Technology (JKUAT), Nairobi, Kenya. ${ }^{3}$ Department of Food, Nutrition and Dietetics, Kenyatta University, Nairobi, Kenya. ${ }^{4}$ Department of Statistics and Actuarial Sciences, Jomo Kenyatta University of Agriculture and Technology (JKUAT), Nairobi, Kenya.

Received: 27 September 2021 Accepted: 11 February 2022

Published online: 24 February 2022

\section{References}

Alemu MH, Olsen SB, Vedel SE, et al (2015) Consumer acceptance and willingness to pay for edible insects as food in Kenya: the case of white winged termites. IFRO work paper, pp 1-27

Anderson JW, Baird P, Davis RH et al (2009) Health benefits of dietary fiber. Nutr Rev 67:188-205. https://doi.org/10.1111/j.1753-4887.2009.00189.x

Arvaniti F, Panagiotakos DB (2008) Healthy indexes in public health practice and research: a review. Crit Rev Food Sci Nutr 48:317-327

Avery A (2004) Red Meat and poultry production and consumption in Ethiopia and distribution in Addis Ababa. Int Livest Res Inst

Barker D, Fitzpatrick MP, Dierenfeld ES (1998) Nutrient composition of selected whole invertebrates. Zoo Biol 17:123-134

Chen Yl, Akre RD (1994) Ants used as food and medicine in China. Food Insects News| 7:8

Christensen DL, Orech FO, Mungai MN, Larsen T, Friis H, Aagaard-Hansen $J$ (2006) Entomophagy among the Luo of Kenya: a potential mineral source? Int J Food Sci Nutr 57:198-203

Green S, Higgins JPT, Alderson P, Clarke M, Mulrow CD, Oxman AD (2010) Cochrane handbook for systematic reviews of interventions. https://onlin elibrary.wiley.com/doi/book/10.1002/9780470712184

Cosgrove M, Flynn A, Kiely M (2005) Consumption of red meat, white meat and processed meat in Irish adults in relation to dietary quality. Br J Nutr 93:933-942. https://doi.org/10.1079/bjn20051427

da Silva Lucas AJ, de Oliveira LM, da Rocha M, Prentice C (2020) Edible insects: an alternative of nutritional, functional and bioactive compounds. Food Chem 311:126022. https://doi.org/10.1016/j.foodchem.2019.126022

de Guevara OL, Padilla P, Garcia L, Pino JM, Ramos-Elorduy J (1995) Amino acid determination in some edible Mexican insects. Amin Acids 9:161-173

Drewnowski A (2005) Concept of a nutritious food: Toward a nutrient density score. Am J Clin Nutr 82:721-732

Drewnowski A, Fulgoni V (2008) Nutrient profiling of foods: Creating a nutrient-rich food index. Nutr Rev 66:23-39. https://doi.org/10.1111/j. 1753-4887.2007.00003.x

Durst P, Johnson D (2010) Forest insects as food: humans bite back. Food and Agriculture Organization of the United Nations, Bangkok, Thailand 
Ebenebe Cl, Amobi MI, Udegbala C et al (2017) Survey of edible insect consumption in south-eastern Nigeria. J Insects as Food Feed 3:241-252. https://doi.org/10.3920/JIFF2017.0002

Eržen N, Rayner M, Pravst I (2015) A comparative evaluation of the use of a food composition database and nutrition declarations for nutrient profiling. J Food Nutr Res. https://. https://doi.org/10.13140/2.1.2096.0000s

Finke MD, DeFoliart GR, Benevenga NJ (1989) Use of a four-parameter logistic model to evaluate the quality of the protein from three insect species when fed to rats1. J Nutr 119:864-871

Garsetti M, De Vries J, Smith M et al (2007) Nutrient profiling schemes: Overview and comparative analysis. Eur J Nutr 46:15-28. https://doi.org/10. 1007/s00394-007-2002-7

Ifr MR, Dfi AM, Castanheira I, et al (2009) EuroFIR Workpackage 1.3, Task Group 4: Guidelines for Quality Index attribution to original data from Scientific literature or reports for EuroFIR data interchange. 35:1-26

Illgner P, Nel E, The S et al (2016) The geography of edible insects in SubSaharan Africa: a study of the mopane caterpillar linked references are available on JSTOR for this article: the geography of edible insects in SubSaharan Africa : a study of the Mopane Caterpillar. Geogr J 166:336-351

Jasinski J, Kulhanek A, Shumaker K (2019) Edible insect workshop engages public in sustainable food conversation. J Ext 57:1

Kinyuru JN, Mogendi JB, Riwa CA, Ndung'u NW (2015) Edible insects-a novel source of essential nutrients for human diet: Learning from traditional knowledge. Anim Front 5:14-19. https://doi.org/10.2527/af.2015-0014

Kinyuru JN (2009) Nutrient composition and utilization of edible termites (Macrotermes subhylanus) and grasshoppers (Ruspolia differens) from Lake Victoria region of Kenya. K. M.Sc. Thesis Jomo Kenyatta Univ Agric Technol

Kitchenham B (2004) Procedures for performing systematic reviews. Keele University, Keele, 33

Lobstein T, Davies S (2008) Defining and labelling 'healthy' and 'unhealthy' food. Public Health Nutr 12:1. https://doi.org/10.1017/\$13689800080025 41

Machovina B, Feeley KJ, Ripple WJ (2015) Biodiversity conservation: The key is reducing meat consumption. Sci Total Environ 536:419-431. https://doi. org/10.1016/j.scitotenv.2015.07.022

Maillot M, Ferguson EL, Drewnowski A, Darmon N (2008) Nutrient profiling can help identify foods of good nutritional quality for their price: a validation study with linear programming. J Nutr 138:1107-1113

Maschkowski G, Hartmann M, Hoffmann J (2014) Health-related on-pack communication and nutritional value of ready-to-eat breakfast cereals evaluated against five nutrient profiling schemes. BMC Public Health 14(1):1-11. https://doi.org/10.1186/1471-2458-14-1178

Masset G (2012) Predictive validity of WXYfm and SAIN,LIM food nutrient profiling models in the Whitehall II cohort. PhD Thesis. University College London

McAfee AJ, McSorley EM, Cuskelly GJ et al (2010) Red meat consumption: an overview of the risks and benefits. Meat Sci 84:1-13. https://doi.org/10. 1016/j.meatsci.2009.08.029

Mike Rayner PS (2009) The UK ofcom nutrient profiling model. London, pp $1-11$

Miller GD, Drewnowski A, Fulgoni V et al (2009) It is time for a positive approach to dietary guidance using nutrient density as a basic principle. J Nutr 139:1198-1202. https://doi.org/10.3945/jn.108.100842

Neacsu M, McBey D, Johnstone AM (2017) Meat reduction and plant-based food: replacement of meat: nutritional, health, and social aspects. Elsevier, Amsterdam

Nowak V, Persijn D, Rittenschober D, Charrondiere UR (2016) Review of food composition data for edible insects. Food Chem 193:39-46. https://doi. org/10.1016/j.foodchem.2014.10.114

Nurnadia AA, Azrina A, Amin I (2011) Proximate composition and energetic value of selected marine fish and shellfish from the West Coast of Peninsular Malaysia. Int Food Res J 18:137-148

Omotoso OT (2006) Nutritional quality, functional properties and anti-nutrient compositions of the larva of Cirina forda (Westwood) (Lepidoptera: Saturniidae). J Zhejiang Univ Sci B 7:51-55. https://doi.org/10.1631/jzus. 2006.B0051

Pali-Schöll I, Binder R, Moens Y et al (2019) Edible insects-defining knowledge gaps in biological and ethical considerations of entomophagy. Crit Rev Food Sci Nutr 59:2760-2771. https://doi.org/10.1080/10408398.2018. 1468731
Pambo KO, Mbeche RM, Okello JJ et al (2018) Intentions to consume foods from edible insects and the prospects for transforming the ubiquitous biomass into food. Agric Human Values 35:885-898. https://doi.org/10.1007/ s10460-018-9881-5

Payne CLR, Scarborough P, Rayner M, Nonaka K (2015) Are edible insects more or less 'healthy' than commonly consumed meats? A comparison using two nutrient profiling models developed to combat over- and undernutrition. Eur J Clin Nutr. https://doi.org/10.1038/ejcn.2015.149

Popay J, Roberts H, Sowden A, Petticrew M, Arai L, Rodgers M, Britten N, Roen K, Duffy S (2006) Guidance on the conduct of narrative synthesis in systematic reviews. Prod ESRC Methods Programme. https://doi.org/10. 13140/2.1.1018.4643

Quinio C, Mccarthy N, Neill JLO (2007) Comparison of different nutrient profiling schemes to a new reference method using dietary surveys. Eur J Nutr 46:37-46. https://doi.org/10.1007/s00394-007-2005-4

Raheem D, Carrascosa C, Oluwole OB et al (2019) Traditional consumption of and rearing edible insects in Africa, Asia and Europe. Crit Rev Food Sci Nutr 59:2169-2188. https://doi.org/10.1080/10408398.2018.1440191

Rayner M, Scarborough P, Boxer A, Stockley L (2005) Nutrient profiles: development of final model final report. Food Standards Agency, Oxford

Rayner M (2013) WHO guiding principles and framework manual for the development and implementation of nutrient profile models. University of Oxford, Washington, DC

Revell BJ (2015) One Man's Meat. 2050? Ruminations on future meat demand in the context of global warming. J Agric Econ 66:573-614. https://doi. org/10.1111/1477-9552.12121

Rumpold BA, Schlüter OK (2013) Nutritional composition and safety aspects of edible insects. Mol Nutr Food Res 57:802-823. https://doi.org/10.1002/ mnfr.201200735

Scarborough P, Rayner M, Stockley L (2007) Developing nutrient profile models: a systematic approach. Public Health Nutr. https://doi.org/10.1017/ \$1368980007223870

Scarborough P, Arambepola C, Kaur A et al (2010) Should nutrient profile models be category specific or across-the-board A comparison of the two systems using diets of British adults. Eur J Clin Nutr 64:553-560. https:// doi.org/10.1038/ejcn.2010.31

Scheidt DM, Daniel E (2004) Composite index for aggregating nutrient density using food labels: ratio of recommended to restricted food components. J Nutr Educ Behav 36:35-39. https://doi.org/10.1016/S1499-4046(06) 60126-7

Schönfeldt HC, Hall NG (2012) Dietary protein quality and malnutrition in Africa. Br J Nutr. https://doi.org/10.1017/S0007114512002553

Sobal J, Bisogni CA (2009) Constructing food choice decisions. Ann Behav Med. https://doi.org/10.1007/s12160-009-9124-5

Soloman M, Ladeji O, Umoru H (2008) Nutritional evaluation of the giant grassropper (Zonocerus variegatus) protein and the possible effects of its high dietary fibre on amino acids and mineral bioavailability. Afric J Food Agric Nutr Dev 8:238-251. https://doi.org/10.4314/ajfand.v8i2.19191

The Food and Drink Federation (2020) Guideline Daily Amounts. http://www. foodlabel.org.uk/label/gda_values.aspx

Townsend MS (2010) Where is the science? What will it take to show that nutrient profiling systems work? Am J Clin Nutr 91:1-4. https://doi.org/10. 3945/ajcn.2010.28450F.2

Van Horn L, Carson JAS, Appel L et al (2016) Recommended Dietary Pattern to Achieve Adherence to the American Heart Association/American College of Cardiology (AHA/ACC) Guidelines: A Scientific Statement from the American Heart Association. Circulation 134:e505-e529. https://doi.org/ 10.1161/CIR.0000000000000462

Wattanachant S, Benjakul S, Ledward DA (2004) Composition, color, and texture of thai indigenous and broiler chicken muscles. Poult Sci 83:123-128. https://doi.org/10.1093/ps/83.1.123

Weru J, Chege P, Kinyuru J (2021) Nutritional potential of edible insects: a systematic review of published data. Int J Trop Insect Sci. https://doi.org/ 10.1007/s42690-021-00464-0

Williams P (2007) Nutritional composition of red meat. Nutr Diet 64:S113S119. https://doi.org/10.1111/j.1747-0080.2007.00197.x

Williamson CS, Foster RK, Stanner SA, Stanner JL (2005) Red meat in the diet. BNF Nutr Bull 30:323-355. https://doi.org/10.1111/j.1467-3010.2005. 00525.x 


\section{Publisher's Note}

Springer Nature remains neutral with regard to jurisdictional claims in published maps and institutional affiliations.

\section{Submit your manuscript to a SpringerOpen ${ }^{\circ}$} journal and benefit from:

- Convenient online submission

- Rigorous peer review

- Open access: articles freely available online

- High visibility within the field

- Retaining the copyright to your article

Submit your next manuscript at $\boldsymbol{\nabla}$ springeropen.com 